\title{
LA COMISIÓN NACIONAL DE PRODUCTIVIDAD INDUSTRIAL Y LA «AMERICANIZACIÓN» DE LA INDUSTRIA DEL CALZADO EN ESPAÑA
}

\author{
JOSÉ ANTONIO MIRANDA ENCARNACIÓN \\ Universidad de Alicante ${ }^{\mathrm{a}}$
}

\begin{abstract}
RESUMEN
Este artículo analiza el papel desempeñado por la Comisión Nacional de Productividad Industrial (CNPI) en el desarrollo de la industria española del calzado. En primer lugar se revisa el carácter de la Comisión y se destacan sus vínculos con la campaña de «americanización» que tuvo lugar en la Europa de postguerra. A continuación se muestra que el calzado fue uno de los sectores prioritarios para la CNPI y se exponen las principales iniciativas desarrolladas por el organismo en esta industria en los años previos a su despegue exportador. En tercer lugar, se demuestra que el sector ya había experimentado una profunda «americanización», en España y en el conjunto de Europa, durante el primer tercio del siglo XX. Finalmente se intenta valorar la repercusión efectiva de las actuaciones de la CNPI.
\end{abstract}

Palabras clave: americanización, franquismo, productividad, industria del calzado

\section{ABSTRACT}

This paper analyses the role played by the National Commission for Industrial Productivity (CNPI) in the development of the Spanish footwear industry. First

a Departamento de Análisis Económico Aplicado, Facultad de CC. Económicas y Empresariales, Universidad de Alicante, 03080 Alicante, España. Miranda@ua.es. 
the nature of the Commission is reviewed highlighting its links with the «americanisation» campaign that took place in post-war Europe. Then, it is shown that footwear was one of the priority sectors for the CNPI, and the main initiatives developed by the organism in this industry in the years prior to the take off of exports are expounded. In third place, it is shown that the sector had already undergone a profound «americanisation» in Spain and in Europe in general during the first third of the 20th century. Lastly, the paper attempts to assess the effective repercussion of the CNPI's actions.

Keywords: Americanisation, Franco regime, productivity, footwear industry JEL Classification: N44, N64, N84, 014

\section{LA COMISIÓN NACIONAL DE PRODUCTIVIDAD INDUSTRIAL Y LA DIFU- SIÓN DE LOS MÉTODOS NORTEAMERICANOS}

Tras la II Guerra Mundial, las dificultades económicas por las que atravesaban los países europeos, frente al nivel de bienestar alcanzado en los EEUU, que habían reforzado su liderazgo internacional, acentuaron en Europa el deseo de imitar el modelo económico norteamericano. Al mismo tiempo, el interés de los EEUU por disminuir la influencia de los partidos y sindicatos comunistas en Europa, y por asegurar la continuidad del propio crecimiento económico norteamericano, se plasmó en un amplio plan de ayuda a los países europeos, el European Recovery Programme, que fue acompañado de una intensa campaña de difusión de la ideología del capitalismo liberal y de los métodos y técnicas de producción norteamericanos ${ }^{1}$.

En este intento organizado de «americanización» de la economía europea, uno de los aspectos a los que se concedió mayor importancia fue la mejora de la productividad del trabajo, que se consideraba el medio más eficaz para aproximarse a la prosperidad del otro lado del Atlántico ${ }^{2}$. Los gestores de la ayuda norteamericana (la Economic Cooperation Administration, sustituida posteriormente por la Mutual Security Agency) pusieron en práctica el Technical Assistance and Productivity Programme e impulsaron la creación de Centros de Productividad en los países beneficiarios del Plan Marshall, hacia los que canalizaron su apoyo

\footnotetext{
${ }^{1}$ Carew (1987), Hogan (1987) y Kipping y Bjarnar (1998).

2 De acuerdo con Schröter $(2002$, p. 44) en este artículo se utiliza el término «americanización», aplicado al ámbito económico, para hacer referencia al proceso de transferencia de «valores, comportamientos, instituciones, tecnología, modelos de organización, símbolos y normas que estaban ampliamente difundidos en los EEUU hacia la esfera económica de la vida en otros países».
} 
organizativo y, sobre todo, financiero ${ }^{3}$. En 1952 ya existían 11 de estos centros en otros tantos países de la OECE. El Reino Unido fue pionero en estas iniciativas con la constitución, en 1948, del Anglo-American Council on Productivity (AACP). Se trataba de una organización en la que estaban representados la patronal y los sindicatos británicos y norteamericanos. Formalmente no estaba ligado ni al Gobierno del Reino Unido ni al de los EEUU, pero su dependencia financiera de los fondos del Plan Marshall (de los dólares norteamericanos y su contrapartida en libras) hizo que el AACP tuviese, de hecho, una estrecha vinculación con ambas administraciones. Cuando se extinguió el European Recovery Programme, en junio de 1952, el AACP fue sustituido por el British Productivity Council, un organismo en el que sí estaba formalmente integrado el Gobierno británico y en el que ya no se encontraban representados los norteamericanos ${ }^{4}$.

En Francia se siguió un modelo distinto al escogido inicialmente por los británicos y no se estableció una institución conjunta con los EEUU, ya que el Gobierno francés deseaba mantener una imagen de mayor independencia. Lo que se hizo fue crear en 1950 un Comité National de la Producivité, en el que participaban el Estado y las asociaciones patronales y sindicales del país, y en el que se incluían también algunos expertos independientes. Además, para ejecutar las políticas concretas vinculadas al incremento de la productividad, se puso en marcha una agencia semioficial, la Asociation Française pour l'Accroissement de la Productivité. También en este caso la finalización del Plan Marshall dio lugar a un replanteamiento del Comité, que en 1953 fue reemplazado por el Commissariat General à la Productivité ${ }^{5}$. En Alemania e Italia se crearon centros similares al francés. En Alemania se reestableció oficialmente, en el verano de 1950, el Rationalisierungs Kuratorium der Deutschen Wirtschaft, adaptando este organismo de 1921, que había servido como cauce para la difusión del taylorismo, a la coyuntura generada por la ayuda americana. Por su parte, el Comitato Nazionale per la Produttività, que dependía directamente de la presidencia del Gobierno, no se concretaría hasta octubre de $1951^{6}$.

Con el objetivo de reforzar y coordinar las diversas campañas nacionales de fomento de la productividad, la Organización Europea de Cooperación Económica (OECE) creó en agosto de 1952 la European Productivity Agency (EPA), que iniciaría sus actividades en 1953. Por entonces, desde 1952, los norteamericanos habían lanzado la Conditional Aid, también conocida como Programa Benton-Moody, un nuevo programa de ayuda a Europa cuyos fondos se destinaron, parcialmente, a promover los proyectos para la mejora de la productividad. De esos fondos obtu-

\footnotetext{
${ }^{3}$ McGlade (1998a y1998b).

${ }^{4}$ Carew (1987, pp. 133-138), Tiratsoo y Tomlinson (1993, pp. 131-152), y Tomlinson (1990).

${ }_{6}^{5}$ Kuisel (1996, pp. 73-79).

${ }^{6}$ Kipping (1997), Carew (1987, pp. 162-164) y Segreto (2002).
} 
vo la EPA la mayoría de su presupuesto y con ellos se financió buena parte de la actuación de los centros nacionales de productividad entre 1952 y $1954^{7}$.

La aparición de la EPA coincidió en el tiempo con un cambio en la línea de actuación de los centros nacionales de productividad. Hasta 1952, las campañas desarrolladas por éstos se habían basado esencialmente en la promoción de visitas de estudio a EEUU por parte de grupos integrados por empresarios, técnicos y trabajadores, con la finalidad de conocer, para poder imitarlos, los métodos de producción y de gestión norteamericanos. A partir de entonces, las misiones a EEUU fueron perdiendo protagonismo y se acentuaron otras líneas de actuación, como la contratación de técnicos norteamericanos para asesorar a las distintas industrias, la realización de cursos, la difusión de informes escritos y material audiovisual, la creación de fábricas-piloto, etc.

Aunque España había quedado al margen del Plan Marshall, los responsables económicos del régimen de Franco también se sumaron al generalizado interés internacional por la productividad y por la imitación de las técnicas norteamericanas. A ello contribuyó poderosamente el nuevo rumbo tomado por las relaciones entre el Gobierno español y el de los EEUU desde comienzos de la década de 1950, que culminaría, en septiembre de 1953, con la firma del Pacto de Madrid ${ }^{8}$. El organismo creado para encargarse de la campaña de productividad fue la Comisión Nacional de Productividad Industrial (CNPI), que se constituyó en mayo de 1952, pero que no comenzó verdaderamente su actividad hasta ya avanzado 1953. Al igual que su homólogo italiano, la CNPI se planteó en principio para un período limitado a tres años. Sus objetivos no eran muy distintos de los declarados por los diferentes centros de productividad ya establecidos en otros países europeos: la finalidad última era aumentar la productividad, para lo cual se encargaría de realizar estudios e investigaciones, divulgar los métodos y técnicas más adecuados y asesorar al Gobierno sobre las medidas a adoptar en este campo. La principal diferencia de la CNPI respecto al conjunto de sus homólogos europeos residía en su carácter y composición, ya que, en lugar de tratarse de una institución tripartita, integrada por representantes no sólo del Gobierno, sino también de la patronal y los sindicatos, era un organismo estatal, directamente dependiente del Ministerio de Industria y compuesto esencialmente por representantes de otros organismos oficiales. La participación de empresarios y trabajadores quedaba limitada, en una Comisión de 14 miembros, a un delegado del Consejo Superior de Cámaras de Comercio y otro de la Delegación Nacional de Sindicatos ${ }^{9}$, algo que, por otra parte, estaba en sintonía con

\footnotetext{
${ }^{7}$ Boel (1998)

${ }^{8}$ Sobre la ayuda americana véase, por ejemplo, Viñas, Viñuela, Eguidazu, Fernández y Florensa (1979), Barciela (2000) y Calvo (2001).

${ }^{9} \mathrm{E} 1$ resto de la Comisión lo formaban seis miembros del Ministerio de Industria, tres de otros Ministerios (Trabajo, Hacienda y Comercio), uno del Instituto Nacional de Estadística, otro del Instituto Nacional de Industria y otro del Instituto Nacional de Racionalización del Trabajo. Véase el Decreto de creación de la CNPI de 1 de mayo de 1952 (BOE de 8 de junio de 1952).
} 
un régimen que había prohibido absolutamente los sindicatos de clase y tan sólo toleraba la existencia de alguna asociación patronal.

Antes de la creación de la CNPI ya existía en España un organismo público encargado de difundir la organización científica del trabajo y fomentar el incremento de la productividad, especialmente mediante publicaciones y la realización de estudios y cursos, el Instituto Nacional de Racionalización del Trabajo (INRT), dependiente del Patronato «Juan de la Cierva» del Consejo Superior de Investigaciones Científicas. Este organismo se creó en 1946 y, a pesar de su corto presupuesto, menos de medio millón de pesetas en el año de su fundación, tenía encomendada una misión muy ambiciosa:

«El desarrollo de cuantas actividades puedan contribuir prácticamente al mejoramiento del rendimiento económico de la producción nacional, por la aplicación y utilización de los modernos métodos de racionalización que comprenden principalmente la organización científica del trabajo, la normalización, la utilización [...] de residuos y desperdicios, así como el estudio de la influencia que pueda ejercer en la formación de los precios las variaciones en el rendimiento de la producción ${ }^{10}$.

Según Guillén (1994, pp. 178-182), el INRT fue una iniciativa apoyada directamente por Juan Antonio Suanzes, que entonces compatibilizaba la presidencia del INI con el cargo de Ministro de Industria, y pronto se convirtió en una organización activa e influyente. Su primer presidente fue Áureo Fernández Ávila, ingeniero naval, como Suanzes, y también vinculado al INI. En la revista oficial del INRT, Racionalización, colaboraron diversos ingenieros militares y navales, pero fue más numerosa la presencia de ingenieros industriales con experiencia en la alta gestión empresarial. Sin embargo, a diferencia de lo sucedido en Alemania, el Instituto de Racionalización no se transformó en el centro coordinador de la campaña de productividad, sino que, por el contrario, se fue desligando progresivamente de esta campaña. Cuando se creó la CNPI se incluyó en ella a un representante del Instituto y, una vez que la Comisión comenzó a actuar, uno de los primeros problemas que se planteó fue la necesidad de actuar coordinadamente con el INRT, que era el representante español en el Comité Internacional de Organización Científica del Trabajo ${ }^{11}$. No obstante, a partir de entonces el Instituto reafirmó su especialización en las tareas de normalización y fue abandonando los temas de productividad en beneficio de la $\mathrm{CNPI}^{12}$.

\footnotetext{
${ }^{10}$ Archivo General de la Administración (en adelante, AGA), Industria, 9371: Documentación de la constitución del INRT.

${ }^{11}$ AGA, Industria, 9488: Actas de la CNPI de 28 de abril y 15 de octubre de 1953.

${ }^{12}$ AGA, Industria, 9366-9372: Memorias del INRT.
} 
Como el Instituto Nacional de Racionalización del Trabajo, la CNPI se encontró en principio con una financiación muy reducida, que apenas le permitió desarrollar proyectos. El despegue en la actividad de la Comisión no llegó hasta mediados de 1954, cuando comenzó a recibir fondos del Programa de Ayuda Técnica Norteamericana asociado al Pacto de Madrid. La CNPI gestionó estos fondos bajo la supervisión de la Oficina de la Comisión Delegada del Gobierno para el Desarrollo de los Convenios con Norteamérica, que dependía de la Presidencia del Gobierno español ${ }^{13}$. Durante los primeros años, igual que había sucedido anteriormente en los centros de productividad europeos, la iniciativa fundamental, a la que se destinaron la mayor parte de los recursos, fue la organización de visitas de estudio al extranjero, principalmente a los EEUU, pero también a los países europeos. Estas misiones comenzaron en 1954 con poca aceptación, debido a que el programa proporcionaba las divisas necesarias, pero los gastos de cada uno de los visitantes debían ser afrontados, en pesetas, por las empresas a las que representaban. Ello hizo que los empresarios privados se mostrasen poco interesados en las misiones; así, en la primera de las visitas organizadas a EEUU, el denominado «proyecto K», de los 21 técnicos enviados a conocer nuevas formas de dirección y organización de empresas, sólo tres representaban a compañías privadas y los restantes 18 pertenecían al INI. A partir de 1955, sin embargo, las misiones de productividad se multiplicaron y contaron con una amplia representación del sector privado, gracias a que la CNPI consiguió que fuesen financiadas con cargo al convenio económico con los EE.UU ${ }^{14}$. A finales de la década, la Comisión recibía de los fondos del programa de Ayuda Técnica Norteamericana, para ésta y otras iniciativas, en torno a diez millones de pesetas anuales ${ }^{15}$. En total, de 1954 a 1962 la CNPI organizó 148 misiones de estudio a los EEUU y a Europa, viajes en los que participaron 962 representantes de varios sectores de la economía española, sobre todo de la industria. Fue una actuación importante, pero muy inferior, en cuanto a los recursos movilizados, a lo que se había hecho en otros países. En Francia, por ejemplo, sólo entre 1949 y 1953 se enviaron 300 misiones a los EEUU, con cerca de 3.000 participantes, y Noruega, un país mucho más pequeño en términos económicos, a finales de 1954 ya había enviado tantas misiones de productividad como las que se organizarían desde España hasta $1962^{16}$.

Las misiones enviadas por la CNPI presentan características muy semejantes a las que organizaron otros centros de productividad europeos. Los grupos, de

${ }_{13}$ Productividad. Revista de la CNPI 30 (enero-febrero-marzo de 1964), pp. 56-58.

${ }^{14} \mathrm{AGA}$, Industria, 9488-9490: Actas de la CNPI de 14 de julio y 11 de octubre de 1954, y de 18 de enero, 15 de abril y 22 de septiembre de 1955 .

${ }_{15}$ AGA, Industria, 9488-9490: Actas de la CNPI de 21 de enero de 1958, 2 de febrero de 1960 y 17 de julio de 1961.

${ }^{16}$ Kuisel (1996, p. 80) y Moel (2002, p. 101). 
unas ocho personas, estuvieron compuestos, en la mayoría de las ocasiones, por empresarios, técnicos especializados y trabajadores, aunque en el caso español la presencia de estos últimos fue menor y, por supuesto, no tuvo el carácter de representación sindical. El objetivo era estudiar un determinado sector productivo $\mathrm{o}$, en menos ocasiones, temas más generales, que afectaban al conjunto de las actividades económicas, como la dirección empresarial o las relaciones laborales. Las estancias solían prolongarse durante seis semanas, en las que se visitaban empresas, universidades, centros de investigación, etc. Los grupos tenían la obligación de redactar una memoria con sus observaciones, texto que habitualmente era publicado por la CNPI con la finalidad de extender la experiencia al conjunto del sector representado por cada misión.

Como puede apreciarse en los Cuadros 1 y 2, el envío de los equipos de estudio comenzó a reducirse a partir de 1959, a la vez que se potenciaban otras actividades, como la contratación de técnicos extranjeros y la realización de cursos especializados. En esta última tarea se experimentó un salto cualitativo a partir de febrero de 1957, cuando entró en funcionamiento la Escuela de Organización Industrial $^{17}$. También desde finales de los años 50 se incrementó la labor editorial y la producción de material audiovisual. Entre 1953 y 1960 la CNPI editó 18 títulos sobre administración de empresas -la mayor parte de ellos traducciones de libros norteamericanos-, 39 memorias de misiones técnicas al extranjero, 8 estudios sobre productividad en diversas industrias, varios libros sobre organización del trabajo y multitud de folletos divulgativos. La Comisión elaboraba igualmente tres publicaciones periódicas: dos con periodicidad mensual (Boletín de Información y Selecciones Técnicas) y una trimestral (Productividad). En total, los ejemplares editados superaron los 140.000 , a los que se sumaron más de 215.000 folletos. De todos ellos, en torno a una cuarta parte se publicó en el año 1960. Además, en sus primeros ocho años de actividad la CNPI produjo 16 películas para la difusión de nuevos métodos y dobló al castellano 55 películas extranjeras. De las últimas, más del 40 por ciento se dobló en el año $1960^{18}$. La actividad de la Comisión evolucionó, por lo tanto, en el mismo sentido que la de los otros centros de productividad europeos, aunque con más de un lustro de retraso ${ }^{19}$.

A pesar de coincidir ampliamente en los objetivos, los métodos de actuación y el origen de sus recursos, la CNPI no se integró plenamente en la red de centros de productividad europeos hasta finales de los años 50. Ello no significa que la Comisión no mantuviese relaciones con sus homólogos europeos. Estas relacio-

\footnotetext{
${ }_{17}$ Sobre la labor de la CNPI en la formación empresarial, véase Puig (2002).

18 Comisión Nacional de Productividad Industrial (1961a, pp. 14-25) y AGA, Industria, 9488-9490: Acta de la CNPI de 5 de marzo de 1957.

19 Donde el Programa de Asistencia Técnica norteamericano tuvo un desarrollo temporal semejante al seguido en España fue en Japón. Véase al respecto Tiratsoo (2000).
} 
CUADRO 1

MISIONES AL EXTRANJERO Y CONTRATOS DE ESPECIALISTAS AMERICANOS REALIZADOS POR LA CNPI, 1954-1962

\begin{tabular}{|l|c|c|c|c|}
\hline \multirow{2}{*}{ Años } & \multicolumn{2}{|c|}{ Misiones } & Especialistas americanos \\
\cline { 2 - 5 } & Proyectos & Participantes & Proyectos & $\begin{array}{c}\mathbf{N}^{\mathbf{0}} \text { de } \\
\text { especialistas }\end{array}$ \\
\hline 1954 & 3 & 31 & - & - \\
\hline 1955 & 13 & 119 & 3 & 3 \\
\hline 1956 & 26 & 178 & 10 & 10 \\
\hline 1957 & 20 & 173 & 3 & 7 \\
\hline 1958 & 21 & 162 & 4 & 4 \\
\hline 1959 & 18 & 85 & 4 & 10 \\
\hline 1960 & 17 & 80 & 9 & 12 \\
\hline 1961 & 14 & 74 & 7 & 7 \\
\hline 1962 & 16 & 60 & 13 & $\mathbf{6 6}$ \\
\hline $\begin{array}{l}\text { Total } \\
(\mathbf{1 9 5 4 - 1 9 6 2 )}\end{array}$ & $\mathbf{1 4 8}$ & $\mathbf{9 6 2}$ & $\mathbf{5 3}$ & \\
\hline
\end{tabular}

Fuente: Productividad. Revista de la CNPI 30, enero-febrero-marzo de 1964.

nes se establecieron muy pronto, especialmente con los centros de Francia e Italia, con los que compartía un particular interés por la actuación en las pequeñas y medianas empresas. También hubo desde un principio contactos con la Agencia Europea de Productividad. Sin embargo, debido a la exclusión de España de la OECE, la Comisión no pudo participar en los proyectos de la Agencia Europea, que era el organismo que coordinaba a los distintos centros nacionales, hasta que el Gobierno español firmó un acuerdo en este sentido en enero de $1958^{20}$.

El decreto de constitución de la CNPI limitaba la duración de este organismo a tres años, por lo que en 1955 se tendría que haber procedido a su disolución. Sin embargo, la Comisión no sólo no desapareció sino que, al contrario, intensificó su actividad. Para regularizar la situación del organismo, un nuevo decreto de 5 de septiembre de 1958 lo constituyó con carácter permanente, a la vez que actualizaba su composición y funciones. Esta renovación normativa se completó en

${ }^{20} \mathrm{~A} G A$, Industria, 9488-9490: Actas de la CNPI de 9 de julio de 1953, 11 de octubre de 1954 y 11 de marzo de 1958. 


\section{CUADRO 2}

NÚMERO DE CURSOS ORGANIZADOS POR LA CNPI, 1953-1961

\begin{tabular}{|l|c|c|c|c|c|c|}
\hline Contenido del curso & $\mathbf{1 9 5 3 - 1 9 5 6}$ & $\mathbf{1 9 5 7}$ & $\mathbf{1 9 5 8}$ & $\mathbf{1 9 5 9}$ & $\mathbf{1 9 6 0}$ & $\mathbf{1 9 6 1}$ \\
\hline Mejora de métodos & 96 & 33 & 39 & 35 & 16 & 13 \\
\hline Administración de salarios & - & 2 & 28 & 25 & 4 & 4 \\
\hline Mercados & 7 & - & 4 & 6 & 6 & 10 \\
\hline Formación de cronometradores & - & 1 & 11 & 19 & 6 & 11 \\
\hline Control de costes & 1 & 6 & 6 & 13 & 14 & 8 \\
\hline Control de calidad & - & - & - & 6 & 2 & 4 \\
\hline Relaciones humanas & 8 & 2 & 6 & 7 & 11 & 7 \\
\hline Planificación y control & 1 & 1 & 20 & 25 & 12 & 10 \\
\hline Tiempos y salarios & 20 & - & - & - & - & - \\
\hline Distribución en planta & 1 & - & - & - & - & - \\
\hline Organización general de empresas & 1 & 5 & 3 & - & 5 & 2 \\
\hline Medida de la productividad & - & - & 2 & - & - & - \\
\hline Dirección de empresas & - & 2 & - & - & - & - \\
\hline Remuneración del trabajo & - & - & - & - & 1 & 2 \\
\hline Temas generales & 40 & 5 & 14 & 10 & 11 & - \\
\hline Coloquios & 59 & 7 & 3 & 2 & - & - \\
\hline Total & $\mathbf{2 3 4}$ & $\mathbf{6 4}$ & $\mathbf{1 3 6}$ & $\mathbf{1 4 8}$ & $\mathbf{8 8}$ & $\mathbf{7 1}$ \\
\hline
\end{tabular}

Fuente: Productividad. Revista de la CNPI 24, julio-agosto-septiembre de 1962.

febrero de 1961, cuando se aprobó un nuevo reglamento. No obstante, la reorganizada Comisión sólo se prolongó tres años más. En 1964, coincidiendo con el arranque de la política de planificación indicativa, tuvo lugar una nueva reforma y un cambio de denominación del organismo, que a partir de septiembre pasó a llamarse Servicio Nacional de Productividad Industrial ${ }^{21}$.

Frente al decreto fundacional de 1952, en la normativa de 1958 se ampliaban los objetivos de la CNPI, añadiendo las tareas que, de hecho, ya venía realizando esta institución y que se potenciaron a partir de entonces, como «desarrollar una

${ }^{21} B O E$ de 15 y 21 de febrero de 1961 , y de 5 de octubre y 3 de noviembre de 1964 . Véase también Productividad. Revista de la CNPI 33 (octubre-noviembre-diciembre de 1964). 
amplia labor de formación y adiestramiento del personal de la industria en aquellas materias que más puedan influir en la mejor administración de las empresas»», «fomentar iniciativas y orientar la puesta en práctica de medidas para el aumento de la productividad por parte de la industria», «ayudar de manera directa a la industria y especialmente a medianas y pequeñas empresas para elevar su productividad mediante una reorganización de las mismas» o «promover el examen colectivo de problemas comunes de las empresas y el intercambio de información sobre experiencias encaminadas a incrementar la productividad». También la nueva normativa ampliaba la composición del organismo, recogiendo las diferentes incorporaciones que se habían ido produciendo desde octubre de 1953. Ello no cambió en absoluto el carácter puramente estatal de la Comisión, ya que los miembros que se habían añadido procedían todos de la Administración. Ni empresarios ni trabajadores vieron aumentada su prácticamente inexistente representación. Donde sí se concedió una cierta presencia a estos grupos sociales fue en las Comisiones Regionales de Productividad. Las Comisiones Regionales, que se habían establecido en Guipúzcoa, Cataluña, Vizcaya y Asturias, tenían la función de auxiliar a la Comisión Nacional en su ámbito territorial correspondiente. En ellas, además de una representación a escala local de los organismos que integraban la Comisión Nacional, se incluían doce vocales, de los cuales seis debían estar vinculados a entidades significativas desde el punto de vista de las actividades de las Comisiones y los otros seis debían proceder de la Organización Sindical, representando tres de ellos a los empresarios y los otros tres a los trabajadores ${ }^{22}$.

\section{LA ACTUACIÓN DE LA CNPI EN LA INDUSTRIA DEL CALZADO}

Desde su misma creación, la CNPI situó a la industria del calzado entre sus prioridades. En la primera reunión de la Comisión, en noviembre de 1952, su presidente, el Ministro de Industria Joaquín Planell, señaló que las industrias más indicadas para que el nuevo organismo iniciase su labor eran las del carbón, textil y calzado, «por su gran importancia en la producción y el nivel de vida» ${ }^{23}$. A estos sectores se dedicaron las tres primeras subcomisiones de trabajo surgidas en la $\mathrm{CNPI}^{24}$. Sin duda, como reflejan las palabras de Planell, el interés por el calzado respondía al considerable volumen de empleo directo de esta industria -más de 40.000 trabajadores- $\mathrm{y}$ a que se trataba de un sector que proporcionaba un bien de consumo básico, al que hasta entonces la mayoría de los españoles había te-

${ }^{22}$ Decreto de constitución con carácter permanente de la CNPI de 5 de septiembre de 1958 (BOE de 14 de noviembre de 1958).

${ }^{23}$ AGA, Industria, 9488: Acta de la CNPI de 17 de noviembre de 1952.

${ }^{24}$ AGA, Industria, 9488: Acta de la CNPI de 28 de abril de 1953. 
nido un acceso muy limitado (Cuadro 3). No obstante, también es muy probable que los dirigentes españoles, ante el ejemplo de lo que estaba sucediendo en Francia e Italia, ya contemplasen las posibilidades que este sector presentaba para convertirse en una importante fuente de divisas ${ }^{25}$.

\section{CUADRO 3}

CONSUMO MEDIO PER CAPITA DE CALZADO DE CUERO EN DIVERSOS PAÍSES, 1952

\begin{tabular}{|l|c|}
\hline \multicolumn{1}{|c|}{ Países } & Pares \\
\hline EEUU & 3,15 \\
\hline Gran Bretaña & 2,78 \\
\hline Cuba & 1,35 \\
\hline Argentina & 1,26 \\
\hline Francia & 1,05 \\
\hline Italia & 0,63 \\
\hline España & 0,38 \\
\hline Portugal & 0,29 \\
\hline
\end{tabular}

Fuente: Comisión Nacional de Productividad Industrial (1957, pp. 126-127)

La respuesta inicial de las empresas de calzado ante la campaña de productividad fue de absoluta indiferencia. Lo que preocupaba a los industriales en los primeros años 50 era la atonía del mercado y los problemas para conseguir inputs básicos, no el bajo rendimiento de una mano de obra que percibía salarios muy bajos. La CNPI, sin embargo, consiguió paulatinamente despertar el interés de los empresarios. Sus actuaciones se concentraron inicialmente en la industria de Mallorca, quizá porque era la que contaba con una mayor tradición exportadora. Primero organizó en Palma unas reuniones para tratar sobre la situación de la productividad en el sector. A continuación, en octubre de 1954, promovió, también en Palma, un curso sobre las mejoras posibles en este campo, impartido por un ingeniero de la Delegación Nacional de Sindicatos, García Fernández, y dos ingenieros del Centro de Estudios de la Productividad del Calzado francés, Petit y Kezler ${ }^{26}$. Dicho curso animó a un

\footnotetext{
${ }^{25}$ Miranda (2001).

${ }^{26}$ Un indicador del escaso interés inicial de los empresarios del calzado por las iniciativas de la CNPI es que a este curso sólo asistieron diez fabricantes. Véase Comisión Nacional de Productividad Industrial (1956, p. 12).
} 
grupo de nueve industriales a realizar una misión de estudio a la industria del calzado francesa, visita organizada por la CNPI y en la que participaron un representante de este organismo y dos del Ministerio de Industria, pero que fue financiada por los propios interesados. A la vuelta de ese viaje, algunas empresas de calzado mallorquinas introdujeron innovaciones importantes en sus métodos de trabajo. Fue el caso de la fábrica de calzado de caballero de Guillermo Nicolau, que consiguió un sustancial incremento de su productividad y que sirvió a la CNPI para filmar un reportaje sobre la renovación de las empresas en esta industria, con el título de «Siempre hay un método mejor». En la primavera de 1955 el interés por el incremento de la productividad ya se había extendido también a la industria valenciana, como lo demuestra la petición realizada por diversos empresarios, entre los que se encontraban varios del calzado, de que se estableciese un Centro de Productividad en Alicante. Dicho centro se constituyó oficialmente en julio y pocos meses después se creó, de nuevo en Palma de Mallorca, un Centro de Productividad de la Industria del Calzado ${ }^{27}$.

Los esfuerzos de la CNPI para impulsar el desarrollo del sector se intensificaron notablemente a partir de 1956. En abril de ese año partió a EEUU una misión, financiada con los fondos de la ayuda americana, compuesta por ocho fabricantes de calzado, procedentes en su mayoría de Baleares, y el ingeniero-jefe de la Delegación de Industria de Palma. También se celebraron cursos y coloquios sobre productividad en la industria del calzado en Alicante y Elda, y se organizó una visita a Mallorca de Mark T. Shaw, el promotor de la política de productividad en la industria del calzado francesa. Pero quizá la actuación más decisiva fue la negociación con las autoridades norteamericanas de un plan conjunto de ayuda para la industria del calzado española. El plan, diseñado por la CNPI, contemplaba la puesta en marcha de una fábrica piloto en Mallorca, propiedad de los miembros del Centro de Productividad de la Industria del Calzado, y el establecimiento de una central de compras y ventas en común. Esta central tendría que ocuparse, además, de realizar controles de calidad, estudios de mercado y tareas de formación de vendedores, directivos y empresarios. El plan incluía igualmente la elaboración de una ambiciosa investigación sobre el mercado del calzado en España y la contratación de dos especialistas norteamericanos, uno dedicado, durante seis meses, a asesorar a las empresas sobre posibles mejoras en la producción y otro, durante doce meses, dedicado al campo de la distribución. Para todo ello se solicitaba una ayuda económica de 800.000 pesetas $^{28}$.

El proyecto no llegó a cuajar como un acuerdo concreto con la International Cooperation Administration, pero la CNPI lo llevó adelante dentro del Programa

${ }^{27}$ AGA, Industria, 9488: Actas de la CNPI de 8 de junio, 11 de octubre y 9 de noviembre de 1954 , y de 15 de abril, 12 de julio y 26 de octubre de 1955.

${ }_{28}$ AGA, Industria, 9488-9490: Actas de la CNPI de 22 de marzo, 13 de junio y 27 de septiembre de 1956; Productividad. Revista de la CNPI 7 (abril-mayo 1958), pp. 39-40. 
de Ayuda Técnica norteamericana. Tan sólo se abandonó la idea de patrocinar la creación de una central de compras y ventas, idea que fue recogida por la iniciativa privada y, antes de acabar el año 1956, se plasmó en la constitución de dos sociedades de este tipo en Palma de Mallorca. El resto de las medidas proyectadas sí se llevó a cabo bajo el impulso de la CNPI, pero de forma paulatina. La fábrica piloto fue organizada por la Sociedad Ibérica Bedeaux y, bajo el nombre comercial de Compañía Juan Frau S.A. (FRAUSA), se inauguró en junio de 1958. El estudio sobre el mercado de calzado en España comenzó en 1957, pero, falto de presupuesto, no fue concluido hasta 1959. Los técnicos norteamericanos se contrataron a través de la empresa de Chicago Wolf Management Engineering Company. El primero fue Herbert V. Sproat, quien efectuó su labor de asesoramiento sobre métodos de fabricación y procedimientos de dirección empresarial en el año 1958, redactando un amplio informe sobre la situación de la industria española del calzado que se publicaría al año siguiente. El segundo, Louis G. Feman, fue contratado entre la CNPI y el Sindicato Nacional de la Piel en 1959 y su labor como asesor en temas de distribución se prorrogó hasta finales de $1961^{29}$.

Además, la Comisión asistió, en febrero de 1958, a la reunión sobre la «Medida de la Productividad en la Industria del Calzado», que se celebró en París, y en el mes de mayo encargó la ejecución de un estudio piloto, en Madrid, sobre la normalización de las medidas del calzado. También a mediados de ese año, como consecuencia del ingreso de la CNPI en la Agencia Europea de Productividad, España se incorporó a un estudio piloto europeo sobre las empresas del sector ${ }^{30}$.

A partir de 1959, con la llegada del asesor norteamericano Louis G. Feman, las actividades de la CNPI en la industria del calzado se volcaron en el fomento de la exportación, especialmente hacia los EEUU. La primera actuación importante en este sentido, realizada en colaboración con el Sindicato de la Piel, consistió en llevar una muestra de la producción española a la feria del calzado de Chicago, en octubre de 1959. La experiencia permitió detectar la falta de adecuación de la oferta española al mercado norteamericano y, con el objetivo de impulsar dicha adecuación, la CNPI compró y puso a disposición de los empresarios hormas americanas, para que elaborasen con ellas las muestras que se iban a presentar en los EEUU. En 1960 se volvió a concurrir a la feria de Chicago y la Comisión estableció un nuevo programa de ayuda a la industria del calzado para el año 1961, esta vez en colaboración no sólo con el Sindicato de la Piel, sino también con la Dirección General de Expansión Comercial del Ministerio de Comercio. Ese programa pre-

\footnotetext{
${ }^{29}$ AGA, Industria, 9488-9490: Actas de la CNPI de 29 de enero, 28 de mayo y 16 de julio de 1957, de 8 de mayo de 1959 y de 14 de noviembre de 1961; Productividad. Revista de la CNPI 8 (julio-agosto 1958), pp. 55-56.

${ }^{30}$ AGA, Industria, 9488-9490: Actas de la CNPI de 21 de enero, 6 de mayo y 23 de julio de 1958. Comisión Nacional de Productividad Industrial (1958 y 1964).
} 
veía: 1) la participación en la feria del calzado de Miami; 2) el fomento de las Agrupaciones de Fabricantes; 3) la organización de seminarios y cursos especiales sobre exportación; 4) la realización de estudios sobre diseño y moda; 5) el comienzo de un plan para mejorar los curtidos españoles y 6) la creación de mecanismos de coordinación entre la industria del calzado y la del curtido, la distribución comercial y otras industrias del vestir. Para todo ello se fijó un presupuesto de 48.000 dólares, a obtener de la Asistencia Técnica de la International Cooperation Administration, y casi 1,4 millones de pesetas, que debían proporcionar los fondos de contrapartida de la ayuda americana ${ }^{31}$.

La atención a la industria del curtido era consecuencia de las críticas que el calzado español había recibido en las ferias internacionales por la mala calidad de sus pieles y la falta de sintonía de éstas con las tendencias de la moda. Ya se había enviado una misión a EEUU para estudiar las empresas de curtidos en 1958, pero en 1961 el apoyo a la modernización del sector se profundizó, dentro del plan de ayuda a la industria del calzado, con la contratación del asesor norteamericano John W. Goodes y la preparación de una nueva misión de estudio, esta vez a Italia, Francia y Alemania ${ }^{32}$.

El año 1961 fue el último en el que la CNPI dedicó una atención preferente a la industria del calzado. En ese año, además de las actividades que ya se han comentado, la Comisión también colaboró con el Sindicato de la Piel en la organización de una conferencia internacional de la OCDE sobre la distribución del calzado, que se celebró en Madrid en octubre. En 1962 simplemente se mantuvieron las medidas para la modernización del curtido que se habían iniciado el año anterior ${ }^{33}$. A partir de entonces y hasta su desaparición como Comisión Nacional de Productividad, en septiembre de 1964, este organismo no puso en práctica ninguna nueva iniciativa de apoyo al sector.

\section{LAAMERICANIZACIÓN DE LA INDUSTRIA DEL CALZADO EN EL PRIMER TERCIO DEL SIGLO XX}

¿Hasta qué punto la labor de la CNPI fue eficaz para promover la modernización y el crecimiento de la industria del calzado en España? Para poder contestar

\footnotetext{
${ }^{31}$ Piel. Revista española de las industrias de la piel, noviembre de 1959, pp. 37-38. Productividad. Revista de la CNPI 13 (octubre-noviembre-diciembre de 1959), y 19 (abrilmayo-junio de 1961), p. 51. AGA, Industria, 9488-9490: Actas de la CNPI de 25 de abril, 20 de julio y 29 de noviembre de 1960, y de 25 de abril de 1961.

${ }^{32}$ Comisión Nacional de Productividad Industrial (1961b). Productividad. Revista de la CNPI 13 (octubre-noviembre-diciembre de 1959); 18 (enero-febrero, marzo de 1961), p. 50; y 20 (julio-agosto-septiembre de 1961), p. 45.

${ }_{33}$ Productividad. Revista de la CNPI 21 (octubre-noviembre-diciembre de 1961), p. 65; 22 (enero-febrero-marzo de 1962), p. 43; y 24 (julio-agosto-septiembre de 1962), p. 55
} 
a esta cuestión resulta conveniente considerar por separado las dos grandes líneas de actuación de la CNPI en el sector: por un lado, los intentos directos de mejorar la productividad; por otro, las medidas de fomento de la exportación.

Las iniciativas desarrolladas por la Comisión en la industria del calzado se centraron en un principio, hasta 1959 aproximadamente, en el incremento de la productividad a través de la renovación técnica y una mejor organización del trabajo. Se trató de traspasar a las empresas españolas la tecnología y los métodos de la industria norteamericana y de los países europeos más avanzados. Los medios utilizados para conseguir este fin fueron principalmente las misiones de estudio y la contratación de especialistas extranjeros. La estrategia era básicamente la misma que se había seguido en otros países de Europa unos cuantos años atrás. Los centros de productividad británico y francés, por ejemplo, enviaron sendos grupos de trabajo del sector a los EEUU ya en 1950. Sin embargo, tampoco entonces dicha estrategia constituyó ninguna novedad, porque los empresarios europeos del calzado, conscientes de la superioridad norteamericana, habían iniciado este tipo de visitas ya a finales del siglo XIX, y los viajes se habían reanudado, tras la II Guerra Mundial, incluso antes de que se recibiese la ayuda del Plan Marshall ${ }^{34}$.

El liderazgo de los EEUU en la industria del calzado se fraguó durante la segunda mitad del siglo XIX, período en el que las empresas norteamericanas consiguieron un incremento espectacular de su productividad. El tiempo medio de trabajo empleado para fabricar un par de zapatos en EEUU era en 1895 casi un 90 por ciento menor que en $1863^{35}$. Ello se debió principalmente al cambio tecnológico, ya que fue en la industria norteamericana donde se desarrolló la tecnología fundamental para mecanizar el sector ${ }^{36}$. La rápida y generalizada difusión de esta tecnología en los EEUU aumentó extraordinariamente la competitividad internacional de su calzado y convirtió a las empresas de este país en el modelo a imitar en todo el mundo.

El progreso tecnológico y la mejora en la productividad no se interrumpieron con la llegada del siglo $\mathrm{XX}^{37}$. Sin embargo, este progreso ya no se tradujo en un incremento de la superioridad de la industria norteamericana sobre la europea. Al contrario, en el primer tercio del siglo XX, en realidad hasta el estallido de la II Guerra Mundial, las empresas europeas lograron acortar distancias en el nivel de productividad. Ello fue posible gracias a la transferencia de tecnología desde los

\footnotetext{
${ }^{34}$ Anglo-American Council on Productivity (1951) y Federation Nationale de l'Industrie de la Chaussure de France (1957, p. 21).

${ }^{35}$ Works Progress Administration (1939, p. 3).

${ }^{36}$ Faler (1981), Brooker (1986), Thomson (1989) y Nadal (1994).

${ }^{37}$ Hoover (1937, p. 206), Works Progress Administration (1939, p. 3) y U. S. Bureau of Foreign and Domestic Commerce (1946).
} 
EEUU. Dicha transferencia se había iniciado poco después de que comenzasen a difundirse las innovaciones en el país de origen, pero no alcanzó un volumen importante hasta el cambio de siglo. La constitución en los EEUU, en 1899, de una gran empresa de maquinaria para el calzado, la United Shoe Machinery Company (USMC), fue decisiva para impulsar el proceso. Esta compañía, con una agresiva estrategia de internacionalización de sus actividades, fue capaz de difundir ampliamente por Europa la misma tecnología que se utilizaba en el calzado norteamericano. Para introducirse en los mercados exteriores y, sobre todo, para trasladar a ellos su estrategia de arrendamiento, la Compañía constituyó empresas filiales en los principales países productores de calzado. La filial española se constituyó oficialmente en 1917, pero, de hecho, la compañía matriz norteamericana contaba con una delegación en el país desde $1906^{38}$.

A través de las filiales de la USMC, las empresas de calzado europeas se equiparon con la más moderna maquinaria norteamericana y esta renovación tecnológica conllevó también una reorganización del trabajo en las fábricas. El proceso supuso una verdadera «americanización» de la industria del calzado en Europa, ya que consistió básicamente en la imitación de las técnicas y métodos desarrollados en los EEUU. Fue una «americanización» a la que colaboraron las delegaciones de empresarios europeos que viajaron a EEUU ${ }^{39}$, pero que descansó fundamentalmente en la expansión de la citada multinacional americana hacia el otro lado del Atlántico. El proceso no resultó homogéneo en todo el continente. Hubo países, como el Reino Unido y Alemania, donde la tecnología americana había alcanzado una gran difusión ya antes de la I Guerra Mundial. En otros, como Italia o España, la transferencia fue más lenta e incompleta. En cualquier caso, al acabar el primer tercio del siglo XX, el conjunto de la industria del calzado europea se había transformado debido a la influencia norteamericana. Prueba de ello es que incluso en España, donde el pequeño tamaño del mercado nacional limitaba las posibilidades de «americanizar» el sector, la industria del calzado recibió más de 11.000 máquinas procedentes de los EEUU entre 1911 y $1930^{40}$.

En la memoria que se redactó tras una misión de la Boot Manufacturers Federation británica a los EEUU, en noviembre de 1918, se aseguraba que la tecnología disponible en las empresas de calzado norteamericanas no era superior a

\footnotetext{
${ }^{38}$ Miranda (1998).

${ }^{39}$ Las visitas a la industria norteamericana, desde finales del siglo XIX, parece que desempeñaron un papel especialmente relevante en la modernización de la industria del calzado británica y en la formación de algunos de los pioneros y de los grandes empresarios de la fabricación mecanizada de calzado en Europa, como el menorquín Jerónimo Cabrisas, el veneciano Giovanni Luigi Voltan y el checoslovaco Tomás Bata. Véase Bondi y Mariacher (1979), Farré-Escofet, Marimon y Surís (1977), Department of Commerce (1924), U. S. Department of Commerce (1929a) y The Leather Trade's Review (january 9, 1929), p. 36.

${ }^{40}$ Archivo de la empresa USM España: Fichas de maquinaria.
} 
la que se encontraba en las europeas ${ }^{41}$. La misma conclusión se desprende de buena parte de los informes sobre la situación de la industria del calzado en los países europeos realizados por los agentes del Departamento de Comercio de los Estados Unidos a partir de la primera década del siglo XX. La citada memoria de la patronal británica señalaba que la ventaja de las empresas norteamericanas residía en la constante aplicación de métodos racionales de organización y, entre estos últimos, destacaba aspectos como la rigurosa planificación de la actividad, la extrema especialización y división del trabajo, la vinculación del salario a la productividad del trabajador y la mayor estandarización del producto. Sin embargo, la industria europea también avanzó en ese sentido, especialmente tras la I Guerra Mundial. Así lo atestiguan, por ejemplo, los informes sobre la cada vez mayor especialización productiva y la mejor organización en las empresas británicas, sobre los logros de las empresas alemanas en la racionalización de la producción y la mejora de los métodos de trabajo, y sobre la aplicación de los más modernos métodos de la producción en masa por parte de la empresa Bata en Checoslovaquia $^{42}$. El fenómeno tampoco fue ajeno a la industria del calzado española, en la que se establecieron algunas grandes empresas de producción en serie, con Segarra como caso más destacado ${ }^{43}$.

\section{EL IMPACTO DE LAS CAMPAÑAS DE LA CNPI}

La II Guerra Mundial volvió a ampliar la brecha que separaba la productividad de la industria del calzado europea en comparación con la de EEUU. Durante la guerra, la industria del calzado de los países beligerantes europeos se vio seriamente afectada por la escasez de mano de obra y materias primas, mientras que la norteamericana disfrutaba de una nueva expansión de su producción, de sus exportaciones y de su productividad. Así, mientras que en el Reino Unido la producción por trabajador era en 1945 sólo un 19 por ciento mayor que en 1935, en los EEUU se había incrementado más de un 45 por ciento entre ambas fechas. Aunque fue una situación transitoria, que comenzó a corregirse poco después de acabar el conflicto, generó entre los empresarios europeos el convencimiento de que era necesario recurrir de nuevo al ejemplo americano para recuperar la competitividad perdida ${ }^{44}$.

La misión británica enviada en 1950 por el Anglo-American Council on Productivity para estudiar la industria del calzado en los EEUU reflejó, en su compa-

\footnotetext{
${ }^{41}$ Les industries du cuir 8, 1920, p. 227.

42 U. S. Department of Commerce (1929a, 1929b y 1937)

${ }^{43}$ Miranda (1998, p. 122).

${ }^{44}$ Anglo-American Council on Productivity (1951, pp. 9-10), y Bureau of Labor Statistics (1965, p. 7)
} 
ración entre las empresas británicas y las de aquel país, una situación muy similar a la existente en la década de 1920. Según la memoria de dicha misión, que tuvo un eco importante en toda la industria del calzado europea, la industria norteamericana presentaba una mayor productividad, pero ésta no se debía ni a un mejor equipamiento tecnológico ni al empleo de métodos de trabajo sustancialmente distintos. La diferencia era el resultado de ese amplio conjunto de elementos, vinculados a las características del mercado y de la sociedad en los EEUU, que ya se venían señalando desde el final de la Gran Guerra como principales responsables de la superioridad del calzado norteamericano. Elementos como la mayor estandarización del producto, la producción a gran escala, el mayor recurso a componentes elaborados por otras empresas o el uso más generalizado de sistemas de incentivos para retribuir a los trabajadores. Por ello, entre otras recomendaciones, la memoria proponía a los fabricantes británicos reducir el número de estilos de calzado, simplificar el producto, estrechar la colaboración con los suministradores de accesorios y componentes, y extender los sistemas de remuneración ligados a la productividad ${ }^{45}$.

El informe de la misión española que, con idéntico fin, organizó la CNPI en 1956 aportó unas reflexiones en la misma línea, pero con una diferencia importante: el atraso técnico de la industria española con respecto a la norteamericana era mucho mayor ${ }^{46}$. El problema tenía su origen en la práctica interrupción del flujo de maquinaria extranjera hacia España desde el estallido de la Guerra Civil y su solución se veía frenada por las dificultades que este tipo de importaciones continuó encontrando en los años 50. No obstante, la actuación de la CNPI en el sector ignoró el problema de la obsolescencia del equipo productivo. La Comisión no realizó ninguna gestión concreta para favorecer la renovación tecnológica en las empresas y, como si se dirigiese a una industria como la británica, suficientemente dotada de equipo productivo y sin grandes problemas para incrementarlo, apostó fundamentalmente por dar a conocer los métodos norteamericanos y por favorecer su introducción, adaptándolos a las características del entorno nacional.

La tendencia de la campaña de productividad en la industria del calzado impulsada por la Comisión se refleja bien en el informe que elaboró el especialista norteamericano Herbert V. Sproat, como resultado de una de las iniciativas clave de dicha campaña. En este informe se señalaban como principales obstáculos al incremento de la productividad seis características de la industria española que no se correspondían con el modelo norteamericano: 1) el pequeño tamaño de las empresas de calzado, que no permitía mecanizar al máximo la producción ni tampoco profundizar en la división del trabajo entre los operarios; 2) la excesiva diversificación del producto en las empresas, que disminuía el rendimiento de la

\footnotetext{
${ }^{45}$ Anglo-American Council on Productivity (1951).

${ }^{46}$ Comisión Nacional de Productividad Industrial (1957, p. 97).
} 
maquinaria y de la mano de obra; 3) las dificultades para obtener un abastecimiento adecuado de materiales, particularmente de suela ya cortada; 4) la falta de una estrategia activa de marketing por parte de las empresas de calzado y la inexistencia en éstas de stocks del producto acabado; 5) la escasa utilización de incentivos salariales directos, y 6) lo rudimentario del sistema de control de la producción. Además, el informe criticaba la escasa calidad media del calzado elaborado en España, que limitaba muy seriamente la competitividad del producto ${ }^{47}$.

Este informe de Sproat, realizado en 1958, ya reflejaba que los esfuerzos anteriores de la CNPI para que la industria del calzado profundizase en su «americanización» apenas obtuvieron resultados prácticos. La misma conclusión puede extraerse de un análisis más detallado de tres de las características tratadas por Sproat (el tamaño de empresa, la especialización y, finalmente, los métodos de organización y control), que eran esenciales en el modelo de producción en masa de los EEUU. Al comenzar la década siguiente, la industria del calzado en España continuaba integrada fundamentalmente por pequeñas y medianas empresas, como puede apreciarse en el Cuadro 4. De hecho, al margen de las labores de propaganda, no se llevó a cabo ninguna política concreta para favorecer la reestructuración del sector. Hubo que esperar hasta 1964 para que se promoviese realmente el aumento de la dimensión empresarial media, a través de las acciones concertadas del Ministerio de Industria ${ }^{48}$. Tampoco en la especialización productiva se realizaron avances importantes en los años 50, como lo demuestra el hecho de que, en la muestra de empresas utilizada por la Agencia Europea de Productividad para la realización de un estudio sobre la industria del calzado en 1958, casi la totalidad de las empresas españolas utilizaran más de dos procedimientos de fabricación diferentes. Además, según el Sindicato de la Piel, al acabar la década las empresas españolas seguían produciendo cerca de 400.000 modelos distintos al año y hasta las más pequeñas empresas presentaban muestrarios con más de 50 modelos ${ }^{49}$. Sobre la introducción efectiva de nuevos métodos de trabajo y de gestión empresarial no se dispone apenas de datos precisos. Hubo iniciativas en este sentido respaldadas por la CNPI, primero en la industria de Baleares y, hacia finales de la década, en la de Alicante $^{50}$, pero todos los informes realizados sobre el sector a principios de los años 60 afirman que la mayoría de las empresas apenas había modificado sus métodos tradicionales. Un indicador indirecto de la escasa modernización en la gestión empresarial es que, hacia 1960, el personal no empleado

\footnotetext{
${ }^{47}$ Comisión Nacional de Productividad Industrial (1959).

${ }^{48}$ Revista de la piel (octubre de 1970), pp. 25-28.

${ }^{49}$ Comisión Nacional de Productividad (1964) y Piel. Revista española de las industrias de la piel (enero de 1959), pp. 6-7.

${ }^{50}$ AHPA, Sindicatos: Informe de los expertos en productividad Martín Bernáldez y Carlos Ballesteros sobre tiempos de trabajo, actividades mínimas y reducción de personal de las empresas de calzado de Elche y textiles de Alcoy.
} 
directamente en la producción (directivos, técnicos y administrativos) no representaba ni siquiera el 5 por ciento de los trabajadores, la mitad que en los EE.UU ${ }^{51}$.

\section{CUADRO 4}

ESTRUCTURA EMPRESARIAL DE LA INDUSTRIA ESPAÑOLA DEL CALZADO, 1963

\begin{tabular}{|l|c|c|c|c|}
\hline \multirow{2}{*}{ Número de trabajadores } & \multicolumn{2}{|c|}{ Calzado de cuero en serie } & \multicolumn{2}{c|}{ Calzado de artesanía } \\
\cline { 2 - 5 } & $\begin{array}{c}\text { Número de } \\
\text { empresas }\end{array}$ & Porcentaje & $\begin{array}{c}\text { Número de } \\
\text { empresas }\end{array}$ & Porcentaje \\
\hline De 1 a 5 & 768 & 42,8 & 903 & 91,0 \\
\hline De 6 a 25 & 788 & 43,9 & 80 & 8,1 \\
\hline De 26 a 50 & 142 & 7,9 & 8 & 0,8 \\
\hline De 51 a 100 & 68 & 3,8 & 1 & 0,1 \\
\hline De 101 a 250 & 22 & 1,2 & 0 & 0,0 \\
\hline De 251 a 500 & 4 & 0,2 & 0 & 0,0 \\
\hline Más de 500 & 1 & 0,1 & 0 & 0,0 \\
\hline Total & $\mathbf{1 7 9 3}$ & $\mathbf{1 0 0 , 0}$ & $\mathbf{9 9 2}$ & $\mathbf{1 0 0 , 0}$ \\
\hline
\end{tabular}

Fuente: Gabinete de Estudios de la Dirección General de Industrias Textiles y Varias (1966, pág. 63).

El fracaso en esta nueva «americanización» de la industria española del calzado no tenía por qué ser necesariamente un factor negativo para el desarrollo del sector. De hecho, los países europeos en que esta industria experimentó un mayor auge en los años 50 no fueron la República Federal Alemana ni el Reino Unido, donde las estructuras productivas eran más semejantes a las norteamericanas, sino Francia e Italia, que presentaban muchas diferencias respecto al modelo imperante al otro lado del Atlántico. El tamaño de empresa refleja fielmente la situación: la media de asalariados por empresa en los EEUU, a mediados de la década, estaba próxima a los 170, en la RFA superaba los 125 empleados y en el Reino Unido llegaba a 90; el calzado francés y, sobre todo, el italiano, en cambio, se elaboraban en empresas con unas dimensiones medias muy inferiores, por debajo

${ }^{51}$ Banco de Crédito Industrial (1962, p. 21) y Bureau of Labor Statistics (1965, p. 4). 
de los 50 trabajadores en el caso de Francia y de los 20 en el de Italia ${ }^{52}$. La industria italiana fue la que mantuvo unas características más distantes del modelo de producción en masa, pero también en Francia se observa una trayectoria diferenciada. La expansión de la industria francesa fue acompañada de una reducción de costes mediante el aumento de la especialización en las empresas y la racionalización del trabajo ${ }^{53}$. No obstante, aparecieron igualmente otras características, como los acuerdos de cooperación entre empresas para la renovación tecnológica y la distribución comercial, que nada tenían que ver con el ejemplo norteamericano y que formaban parte de un modelo de producción alternativo, basado en las pequeñas y medianas empresas, en el que se compatibilizaba la flexibilidad productiva con la competitividad vía precios.

El espectacular crecimiento de la industria del calzado en Francia e Italia no se apoyó principalmente en la imitación de los métodos norteamericanos, sino en su capacidad para fabricar, con bajos costes laborales, el tipo de producto que demandaba el mercado internacional. La novedad en este mercado respecto a épocas anteriores residía en tres aspectos fundamentalmente: 1) la mayor capacidad de consumo en los países occidentales, como consecuencia del rápido crecimiento económico; 2) la mayor influencia de la moda, que requería un producto más variado y diferenciado, y 3) las mayores facilidades para las exportaciones e importaciones, gracias a la generalizada tendencia hacia la liberalización de los intercambios internacionales y a las mejoras en el transporte. Francia, primero, e Italia, a continuación, se convirtieron en países con un calzado muy competitivo debido a que ofrecían, a bajo precio, un producto diversificado y ajustado a la moda. El despegue francés fue más temprano, pero también más efímero. Francia ya exportaba en 1955 casi 10 millones de pares de calzado de cuero y cinco años después superaba los 30 millones. Sin embargo, a finales de los años 60 se había convertido en un importador neto de calzado. La industria italiana, en cambio, no superó el volumen de las exportaciones francesas hasta principios de la década de 1960 , pero su expansión se acentuaría a partir de entonces, rebasando los 65 millones de pares en 1970 y consolidándose en la cima de la exportación mundial. En ambos casos, especialmente en el de Italia, la estructura de pequeñas empresas otorgaba una gran flexibilidad y diversidad a la producción, mientras que la concentración de buena parte de estas empresas en distritos industriales generaba todo un conjunto de economías externas que compensaba la pérdida de economías de escala y otros inconvenientes asociados a la pequeña dimensión empresarial ${ }^{54}$.

\footnotetext{
${ }^{52}$ Banco de Crédito Industrial (1962, p. 14), y Comisión Nacional de Productividad (1959, p. 7)

${ }^{53}$ Comisión Nacional de Productividad Industrial (1957, pp. 9-11; 1964).

${ }_{54}$ Miranda (2001). Sobre las características y ventajas de la producción flexible y su plasmación histórica, véase Sabel y Zeitlin (1997) y Scranton (1998).
} 
En un principio, los empresarios españoles interesados en la modernización de la industria del calzado y la Comisión Nacional de Productividad Industrial tuvieron como principal referencia en este campo a Francia, donde la industria había conseguido una importante mejora de su productividad en la primera mitad de la década de $1950^{55}$. Por ello se recurrió inicialmente al asesoramiento de los técnicos franceses y la primera misión del calzado organizada por la CNPI se envió al país vecino. Este planteamiento no se mantuvo, sin embargo, con el paso del tiempo. Al menos desde 1956 la atención se volcó hacia los EEUU, de donde se recibía la financiación para las campañas de productividad y donde existía toda una red de apoyo material y organizativo para las mismas. Probablemente fue un cambio de estrategia inevitable, pero condenado a ser poco eficaz. La industria norteamericana continuaba siendo líder en productividad del trabajo, pero también operaba en un entorno completamente distinto al español y su modelo de crecimiento ya estaba manifestando claros síntomas de encontrarse agotado. Así, el producto por hora-hombre de trabajo en la industria del calzado de EEUU en 1965 era sólo un 2,5 por ciento mayor que en 1959 y la productividad multifactorial, es decir, la que mide la relación del producto no sólo con el trabajo, sino también con el capital y los bienes intermedios empleados en su fabricación, había descendido un 3,2 por ciento respecto al nivel de $1959^{56}$. De hecho, desde los años 50 el calzado norteamericano estaba retrocediendo, incluso en su propio mercado nacional, ante la competencia de países con características más próximas a las de España y que podían constituir, por ello, un mejor modelo a seguir. Resulta muy significativo que los propios integrantes de la misión enviada a EEUU recurriesen más al ejemplo francés que al norteamericano cuando querían mostrar en su informe las posibilidades de mejorar la producción en las empresas españolas de calzado.

Ahora bien, ¿cual fue el resultado concreto de la campaña de productividad? Si se observa la evolución del número de pares fabricados por trabajador en la industria española del calzado, parece que se consiguió un progreso muy importante. Se pasó de menos de 500 pares en 1950 a más de 700 ya en $1958^{57}$. Un incremento de más del 50 por ciento en ocho años. No obstante, la comparación con otros países, que hay que manejar con precaución porque los datos no siempre están elaborados con el mismo criterio, muestra que el nivel de productividad alcanzado a finales de los años 50 todavía era muy bajo, sobre todo si se tiene en cuenta que la jornada laboral en España era de las más largas de Europa. La pro-

\footnotetext{
${ }^{55}$ Federation Nationale de 1'Industrie de la Chaussure de France (1957, pp. 20-22) e Instituto Nacional de Investigaçao Industrial (1969, pp. 58-67).

${ }^{56}$ Duke y Usher (1989).

${ }^{57}$ Anuarios Estadísticos de España, varios años, y Piel. Revista española de las industrias de la piel (mayo de 1963).
} 
ducción por trabajador en el calzado español no representaba ni el 85 por ciento de la media de los países de la OECE y se situaba un 20 por ciento por debajo del nivel de la industria francesa y más de un tercio por debajo del mismo dato para la industria italiana ${ }^{58}$. El crecimiento de la productividad, por lo tanto, se logró gracias al bajísimo nivel de partida y todo parece indicar que fue consecuencia más de la progresiva superación de los obstáculos que habían mantenido estancado el sector en la postguerra que de una incorporación generalizada de nuevos métodos y técnicas.

La bajísima productividad con la que la industria española del calzado inició los años 50 era, en buena parte, un legado de la Guerra Civil y la situación económica de postguerra. Una de las bases del problema residía en el escaso consumo interno de calzado de cuero. Debido a la disminución real de la renta per capita, este consumo todavía se situaba a comienzos de los años 50 por debajo del nivel de antes de la Guerra Civil. Sin embargo, la capacidad productiva era sustancialmente mayor que en 1936, de modo que la producción apenas representaba las dos terceras partes de la capacidad productiva. Esta capacidad se había incrementado durante el conflicto armado a causa de la demanda militar, especialmente en la zona que estuvo bajo control de las tropas de Franco, ya que el grueso de la industria del calzado tradicional quedó en territorio republicano. Al acabar la guerra tuvo lugar una nueva efímera expansión de la capacidad productiva, impulsada por la demanda civil insatisfecha ${ }^{59}$. A partir de entonces, el consumo se redujo notablemente, pero el sistema de intervención estatal sobre el sector y la situación de la economía española en los años 40 contribuyeron a mantener la estructura productiva anquilosada, sin apenas cambios. La existencia, hasta junio de 1952, de un sistema de distribución centralizada de las materias primas a precio tasado, unida a las enormes dificultades para conseguir maquinaria y al bajo coste de la mano de obra, permitieron que el número de empresas y trabajadores no decreciese, aunque sí lo hizo y mucho la productividad ${ }^{60}$.

El fin del sistema de cupos de materias primas trajo consigo la desaparición de las empresas más ineficientes. A ello se sumaron, para incrementar la productividad del calzado en los años 50, la mejor oferta de maquinaria, la mayor disponibilidad de materias primas y el crecimiento de la demanda interna. Fueron estos factores los verdaderos responsables del aumento de la productividad y no las actividades de la CNPI. Estos factores sacaron a la industria del calzado de su anquilosamiento y si no lograron un mayor avance en la productividad fue porque todavía se veían limitados por la política económica de la Dictadura y por la situación económica del país. La oferta de maquinaria mejoró gracias a que los produc-

\footnotetext{
${ }^{58}$ Banco de Crédito Industrial (1962, p. 36)

${ }^{59}$ AGA, Sindicatos, 2618: Asamblea Regional de Fabricantes de Calzado

${ }^{60}$ Miranda (1998, pp. 201-300).
} 
tores nacionales de estos bienes de equipo dispusieron de un abastecimiento más regular de hierro y energía, y a que se pudo importar más tecnología. Sin embargo, esas importaciones continuaron siendo difíciles, debido a la intervención estatal sobre el comercio exterior, y la renovación tecnológica se vio entorpecida por la legislación sobre nuevas industrias, que se mantuvo en vigor hasta los años $60^{61}$. Los registros de la Unión de Maquinaria para el Calzado, la principal compañía del sector en España, muestran que las empresas recibieron un mayor número de maquinaria a partir de $1950 \mathrm{y}$, sobre todo, desde mediados de la década, pero las dificultades para realizar importaciones determinaron que se tuviese que recurrir ampliamente al acondicionamiento de maquinaria usada. Por todo ello, al comenzar los años 60, se calculaba que la industria del calzado necesitaba renovar todavía más de la mitad de su equipo productivo ${ }^{62}$.

Por lo que respecta al abastecimiento de materias primas, la liberalización del comercio interior de pieles curtidas y las mayores importaciones de cueros lograron terminar con la crítica escasez de materiales que había atenazado a la industria en los años 40. No obstante, la intervención sobre el comercio exterior continuó creando en la década siguiente desajustes entre los materiales demandados por el mercado y los efectivamente disponibles, además de que alimentaba las irregularidades en la calidad y el precio de estos inputs y, en consecuencia, fomentaba la especulación. Estos problemas, acentuados por la absoluta prioridad de la que seguían disfrutando los pedidos militares, constituían una traba importante para el incremento de la productividad, pero sobre todo dificultaban la mejora de la calidad y de la capacidad de las empresas para ofrecer un producto homogéneo y para respetar los plazos de entrega, que eran algunas condiciones básicas para que el calzado español pudiese penetrar con éxito en el mercado exterior ${ }^{63}$.

El crecimiento económico de los años 50 trajo consigo una mayor capacidad adquisitiva por parte de la población $\mathrm{y}$, por lo tanto, un incremento de la demanda de bienes de consumo, particularmente desde mediados de la década. Esta ampliación de la demanda colaboró igualmente a la mejora de la productividad, pues permitió a la industria aumentar el grado de utilización de su capacidad productiva. Ahora bien, el impulso recibido por el sector no fue mayor porque, como se partía de un nivel de renta y de consumo tan bajo, el aumento de la demanda se desvió en buena parte a un bien inferior, el calzado textil, que todavía en 1960 tuvo en España unas ventas muy superiores a las del calzado de cuero, algo insólito entre los países de Europa occidental ${ }^{64}$.

\footnotetext{
${ }^{61}$ Buesa (1984).

${ }^{62}$ Archivo de la empresa USM España: Acta de la junta general de 15 de mayo de 1953 y Fichas de maquinaria; Banco de Crédito Industrial (1962, p. 35) y Piel (octubre de 1962), pp. 66-67.

${ }^{63}$ AGA, Sindicatos, 4503 (correspondencia del Sindicato de la Piel con la Secretaría General del Movimiento) y 2618 (Actas de la Asamblea Regional de Fabricantes de Calzado).

${ }^{64}$ Piel (mayo de 1962), p. 13, y Comisión Nacional de Productividad Industrial (1961b).
} 
La CNPI contribuyó, sin duda, a despertar el interés de los empresarios por una mejor organización de sus empresas y la búsqueda de una mayor productividad, pero apenas aportó realizaciones concretas en este sentido. Por un lado, debido a que apostó por un modelo de industria cuyas características difícilmente se podían trasplantar a la situación española más de lo que ya se había hecho en el primer tercio del siglo XX. Por otro, debido a que la Comisión no dispuso de medios para ir más allá de las tareas de formación y propaganda. Las verdaderas razones que impulsaron la mejora de la productividad y el crecimiento del sector fueron los cambios en la situación económica del país, asociados al paulatino desmantelamiento del intervencionismo autárquico. Cuando el proceso de transformación se aceleró, desde el comienzo de los años 60 , también lo hizo la modernización de la industria del calzado. La CNPI no tuvo nada que ver con estos cambios, ni siquiera manifestó la necesidad de éstos en sus informes. Al fin y al cabo, se trataba de un organismo absolutamente controlado por la Administración franquista, del que no cabía esperar ningún tipo de enfrentamiento con el Régimen.

El otro campo de actuación de la CNPI en la industria del calzado fue el fomento de las exportaciones, que absorbió el grueso de las iniciativas para este sector desde 1959. La Comisión trabajó en este campo en coordinación con el Ministerio de Comercio y el Sindicato Nacional de la Piel. Su estrategia consistió básicamente en dar a conocer el calzado español en los EEUU y en introducir a los fabricantes españoles en el mercado norteamericano. Los medios disponibles fueron pobres: no se fue más allá de contratar asesores norteamericanos y de organizar y apoyar financieramente la presencia de las empresas españolas en las ferias de calzado de los EEUU. Sin embargo, el planteamiento se demostró muy acertado. No hay que olvidar que en esos momentos los EEUU ya se habían convertido en el principal importador mundial de calzado, con una clara preferencia por los productos de moda fabricados en la Europa mediterránea, y esta tendencia se acentuaría con el paso del tiempo ${ }^{65}$. Además, la constitución de la CEE, de la que España había quedado fuera, planteaba un futuro de incertidumbre para las exportaciones a los mercados europeos.

En realidad, las ventas de calzado español al exterior crecieron muy poco hasta la década de 1960, sobre todo si se comparan con las francesas o las italianas, pero no porque fallase la tarea de promoción. Esta tarea parece que colaboró eficazmente a que el mercado norteamericano, en el que el calzado español apenas había estado presente hasta mediados de los años 50 , fuese el principal destino de la exportación española de calzado ya desde finales de la década, y a que se generase entre los empresarios españoles un conocimiento de dicho mercado que resultaría clave en la posterior expansión exportadora.

${ }^{65}$ Szenberg, Lombardi y Lee (1977). 
En esta ocasión, la estrategia de la CNPI fue correcta, pero sus efectos estuvieron de nuevo supeditados a las posibilidades del entorno económico en el que se desenvolvía la industria. Las exportaciones de calzado a los EEUU tardaron en despegar porque la industria española no estaba, en los años 50, en condiciones de suministrar el tipo de producto requerido por este mercado. Así se puso de manifiesto en la primera participación de los empresarios españoles en la Feria de Chicago, en 1958, en la que apenas se consiguieron pedidos. Según el asesor norteamericano Louis G. Feman, una de las razones fundamentales de que el calzado español no tuviese una buena aceptación en el mercado americano residía en el hecho de que se trataba de un producto que no reunía la calidad necesaria ni en la piel utilizada, ni en el diseño, ni en la fabricación ${ }^{66}$. Después de más de una década trabajando con materias primas escasas y de mala calidad, para un mercado interior pobre, incapaz de demandar nuevos diseños ni tendencias de moda, la producción de calzado española necesitaba una profunda reconversión para poder expandirse en el mercado internacional. Esa reconversión requería tiempo y, principalmente, un entorno favorable. En la década de 1950, cuando todavía se sufrieron problemas de abastecimiento de materias primas y de suministro de bienes de equipo, ese entorno favorable no existió. Por ello las iniciativas de promoción comercial no fructificarían verdaderamente hasta los años 60 .

En la década de 1960, especialmente a partir de 1964, la industria española del calzado sí conoció un crecimiento extraordinario, que no se interrumpiría hasta 1974. Entre estas dos últimas fechas, el número de pares producidos aumentó en cerca de 80 millones y, de ellos, casi las dos terceras partes se dirigieron al mercado exterior. El principal destino de estas exportaciones fue, con gran diferencia, el mercado norteamericano. Ello hizo que una parte fundamental de la industria produjese en función de las necesidades y los gustos de la población de los EEUU. Haciendo un juego de palabras, puede decirse que fue otra forma de «americanización».

\section{CONCLUSIONES}

El fenómeno de la «americanización» económica de Europa ha sido objeto de una intensa investigación en los últimos años. Ello ha proporcionado un gran avance en el conocimiento de los canales de transmisión de las instituciones norteamericanas a Europa. Sin embargo, todavía se sabe muy poco sobre los resultados efectivos del proceso. Este trabajo ha intentado realizar una modesta aportación en ese sentido. Por supuesto, la industria del calzado tiene unas características muy específicas, que diferencian claramente su evolución de la de otros

\footnotetext{
${ }^{66}$ Piel. Revista española de las industrias de la piel (noviembre de 1959), p. 38
} 
sectores. No obstante, también resulta un caso particularmente interesante, ya que la mayoría de los trabajos disponibles sobre la influencia americana se han centrado en las industrias básicas y, como ha señalado Zeitlin (2000, pág. 20), para profundizar en la americanización de postguerra es necesario tratar especialmente las industrias ligeras de bienes de consumo.

Los métodos de producción y gestión empresarial en EEUU eran muy diversos, como cabía esperar en una economía tan amplia, rica y variada. A pesar de ello,

«para los contemporáneos de ambos lados del Atlántico y del Pacífico, el 'modelo americano' significaba sobre todo producción en masa -fabricación a gran escala de bienes estandarizados utilizando maquinaria específica y trabajo predominantemente no especializado- junto con la utilización de 'sistemáticas' técnicas de gestión empresarial, estructuras organizativas y servicios de investigación y comercialización» ${ }^{67}$.

Este modelo es el que la CNPI intentó trasladar a la industria española del calzado, pero su iniciativa, apoyada principalmente en las misiones de productividad y el asesoramiento de técnicos norteamericanos, apenas obtuvo resultados positivos en esa línea. Las empresas españolas aumentaron su mecanización y mejoraron su eficiencia a lo largo de los años $50 \mathrm{y}$, sobre todo, en la década de 1960, pero siguiendo una estrategia competitiva muy distinta a la que se proponía desde la CNPI y que se asociaba con la industria americana. De forma semejante a lo sucedido en Italia, el calzado español crecería fundamentalmente en función de la demanda externa y apoyando su competitividad en la flexibilidad productiva y la diversificación del producto que proporcionaba la estructura de pequeñas empresas. Fue una estrategia con éxito y que se difundiría a otros muchos sectores en los años 70 y $80^{68}$.

La industria española del calzado no constituye un ejemplo aislado por su escasa aceptación de las propuestas «americanizadoras». La literatura existente muestra ya varios casos semejantes en Europa de otros sectores en que la campaña de productividad tampoco consiguió introducir transformaciones significativas, al menos a corto plazo, como la industria eléctrica alemana ${ }^{69} \mathrm{o}$ las industrias francesas del aluminio, el material eléctrico y la siderurgia ${ }^{70}$. Para el calzado español, los esfuerzos de la CNPI no contribuyeron de manera importante a la mejora de la productividad, entendiendo ésta en un sentido técnico, de incrementar el

\footnotetext{
${ }^{67}$ Zeitlin (2000, pp. 2-3).

${ }^{68}$ Véase, por ejemplo, Piore y Sabel (1990).

${ }^{69}$ Feldenkirchen (2002).

${ }^{70}$ Leroux-Calas (2002), Lanthier (2002), Kipping (2000) y Mioche (2002).
} 
producto por unidad de trabajo, ni a impulsar la producción en masa y la organización fordista del trabajo. El calzado español ya había asimilado antes de la guerra civil la tecnología norteamericana y en la década de 1950 tan sólo se recuperó parte del terreno perdido en este campo desde 1936. Sin embargo, ello no quiere decir que la Comisión no influyera en el sector ni, principalmente, que tampoco lo hicieran las relaciones entre España y los Estados Unidos.

El caso de la industria española del calzado recuerda lo que ha sido señalado por R. Locke respecto a la influencia de los contratos militares norteamericanos en favor de la transferencia de tecnología a Europa ${ }^{71}$. Al igual que las compras militares favorecieron la renovación en empresas como Fiat, Rolls Royce o Renault, las importaciones de calzado por parte de los EEUU, en aumento desde los años 50 y masivas desde mediados de los 60, impulsaron decisivamente la modernización de esta industria en España. Parece que la CNPI contribuyó eficazmente a establecer los primeros vínculos entre la oferta española y la demanda norteamericana de calzado. De esta manera sí que hubo una aportación relevante por parte de la Comisión y, por lo tanto, de las instituciones americanas de asistencia técni$\mathrm{ca}$, en el desarrollo de la industria. Lo que no se puede concretar de momento es hasta qué punto la actitud de la Administración de los EEUU fue decisiva para impulsar dichas importaciones. El calzado español no tuvo un tratamiento arancelario preferente en EEUU, pero queda por investigar si se realizaron presiones políticas sobre los empresarios norteamericanos para que canalizasen su demanda de calzado hacia el «aliado» español. De momento, la información disponible parece indicar que no fue así y que los mayoristas norteamericanos se dirigieron hacia el calzado español libremente, guiados tan sólo por razones económicas, buscando un suministrador barato de calzado atractivo.

\section{FUENTES}

Archivo de la empresa USM España, Fichas de Maquinaria y Libros de Actas. Archivo General de la Administración (AGA), Fondos de Industria y Sindicatos. Archivo Histórico Provincial de Alicante (AHPA), Fondo de la Organización Sindical.

\section{BIBLIOGRAFÍA}

Anglo-American Council on Productivy (1951): Productivity Team Report on the Footwear Industry. Londres: Anglo-American Council on Productivity.

Anuario Estadistico de España. Madrid (varios años).

\footnotetext{
${ }^{71}$ Recojo la cita a través de Barjot $(2002$, p. 17).
} 
BANCo DE CRÉdito Industrial (1962): Informe de carácter general sobre la industria del calzado en España. s.1.: Servicio de Estudios del Banco de Crédito Industrial.

BARCiEla, C. (2000): La ayuda americana a España (1953-1963). Alicante: Universidad de Alicante

BarJot, D. (2002): «Introduction», en D. Barjot (ed.), Catching Up with America. Poductivity Missions and the Diffusion of American Economic and Technological Influence after the Second World War. París: Presse de l'Université de Paris-Sorbonne, pp. 13-50.

Boel, B. (1998): «The European Productivity Agency», en M. Kipping y O. Bjarnar (eds.), The Americanisation of European Business. The Marshall Plan and the Transfer of US Management Models. Londres: Routledge, pp. 37-54.

Bondi, F. y Mariacher, G. (1979): La calzatura della Riviera del Brenta. Storia \& Disegn. Venecia: Cavallino

Brooker, K. B. (1986): «The transformation of the small master economy in the boot and shoe industry, 1887-1914: with special reference to Northampton». University of Hull. Tesis doctoral.

Buesa, M. (1984): «Las restricciones a la libertad de industria en la política industrial española (1938-1963)». Información Comercial Española 606, pp. 107-121.

Bureau of Labor Statistics (1965): Indexes of Output Per Man-Hour Footwear Industry, 1947-63. Washington: U. S. Department of Labor.

CAlvo, O. (2001): «iBienvenido, Mister Marshall! La ayuda económica americana y la economía española en la década de 1950». Revista de Historia Económica XIX, pp. $253-276$

CArew, A. (1987): Labour under the Marshall Plan. The Politics of Productivity and the Marketing of Management Science. Manchester: Manchester University Press

Comisión Nacional de Productividad Industrial (1956): Memoria de las visitas realizadas a fábricas francesas de calzado por un grupo de fabricantes mallorquines, con indicación de las principales mejoras observadas para el aumento de su productividad. Madrid: CNPI.

- (1957): La industria del calzado en Estados Unidos. Madrid: CNPI

- (1958): Normalización de medidas del calzado (Estudio piloto en Madrid). Madrid: CNPI.

- (1959): Productividad de la industria española del calzado. Madrid: CNPI

- (1961a): La CNPI y sus actividades en 1960. Madrid: CNPI.

- (1961b): Industria del curtido: Memoria presentada a la CNPI por el equipo de curtidos enviado a los Estados Unidos. Madrid: CNPI.

- (1964): Comparación inter-empresas, un estudio piloto en la industria europea del calzado. Madrid: CNPI

Department of Commerce (1924): Shoes, Leather, and Hides in Great Britain. Washington: Government Printing Office.

Duke, J. y Usher, L. (1989): «Multifactor Productivity Slips in the Nonrubber Footwear Industry». Monthly Labor Review (Abril), pp. 32-38.

FALER, P. G. (1981): Mechanics and Manufacturers in the Early Industrial Revolution. Lynn, Massachusetts, 1780-1860. Albany: State University of New York Press.

Farre-Escofet, E., Marimon, R. y Suris, J. M. (1977): La via menorquina del creixement. Barcelona: Banca Catalana-Servei d'Estudis. 
Federation Nationale de L'Industrie de la Chaussure de France (1957): Les industries $d u$ cuir. L'industrie de la chaussure. París : Conseil National du Patronat Français et Institut National de la Statistique et des Études Économiques.

Feldenkirchen, W. (2002): «Productivity Missions and the German Electrical Industry», en D. Barjot (ed.), Catching Up with America. Poductivity Missions and the Diffusion of American Economic and Technological Influence After the Second World War. París: Presse de 1'Université de Paris-Sorbonne, pp. 285-300.

Gabinete de Estudios de la Dirección General de Industrias Textiles y Varias (1966): $L a$ industria del calzado en España. Madrid: Servicio de Publicaciones del Ministerio de Industria.

Guillén, M. F. (1994): Models of Management. Work, Authority, and Organization in a Comparative Perspective. Chicago: The University of Chicago Press.

Hogan, M. (1987): The Marshall Plan: America, Great Britain and the Reconstruction of Western Europe, 1947-1952. Cambridge: Cambridge University Press.

Hoover, E. M. (1937): Location Theory and the Shoe and Leather Industries. Cambridge (MA): Harvard University Press.

Industries du cuir, Les (1920).

Instituto Nacional de Investigaçao Industrial (1969): Estudos de produtividade, $n^{\circ} 9$. Medidas directas de produtividade na indústria de calçado mecânico. Lisboa: Secretaria de Estado da Industria-Ministério da Economia.

Kipping, M. (1997): «Consultancies, Institutions and the Diffusion of Taylorism in Britain, Germany and France, 1920s to 1950s». Business History 39 (4), pp. 67-83.

— (2000): «A Slow and Difficult Process: the Americanization of the French Steel-Producing and Using Industries after the Second World War», en J. Zeitlin y G. Herrigel (eds.), Americanization and Its Limits. Reworking US Technology and Management in PostWar Europe and Japan. Oxford: Oxford University Press, pp. 209-235.

KipPing, M. y Buarnar, O. (eds.), (1998): The Americanisation of European Business. The Marshall Plan and the Transfer of US Management Models. Londres: Routledge.

Kuisel, R. (1996): Seducing the French. The Dilemma of Americanization. Berkeley: University of California Press.

Lanthier, P. (2002): «France and US Industrial Know-How: the Case of Electrical Engineering, 1945-60», en D. Barjot (ed.), Catching up with America. Poductivity Missions and the Diffusion of American Economic and Technological Influence after the Second World War. París: Presse de 1'Université de Paris-Sorbonne, pp. 301-314.

Leather Trade's Review, The (1929).

Leroux-Calas, M. (2002): «The Influence of the Productivity Missions on R\&D in France: The Case of AFC-Péchiney», en D. Barjot (ed.), Catching Up with America. Poductivity Missions and the Diffusion of American Economic and Technological Influence after the Second World War. Paris: Presse de 1'Universite de Paris-Sorbonne, pp. 395-404.

McGlade, J. (1998a): «From Business Reform Programme to Production Drive. The Transformation of US Technical Assistance to Western Europe», en M. Kipping y O. Bjarnar (eds.), The Americanisation of European Business. The Marshall Plan and the Transfer of US Management Models. Londres: Routledge, pp. 18-34.

- (1998b): «The Big Push: the Export of American Business Education to Western Europe After the Second World Wary, en L. Engwall y V. Zamagni (eds.), Management Education in Historical Perspective. Manchester: Manchester University Press, pp. 50-65. 
Mioche, P. (2002): «The Mistakes of Productivity Missions to the United States: The Case of the French Steel Industry», en D. Barjot (ed.), Catching Up with America. Poductivity Missions and the Diffusion of American Economic and Technological Influence after the Second World War. París: Presse de l'Université de Paris-Sorbonne, pp. 265-276.

Miranda, J. A. (1998): La industria del calzado en España (1860-1959). La formación de una industria moderna y los efectos del intervencionismo estatal. Alicante: Generalitat Valenciana e Instituto de Cultura «Juan Gil-Albert».

- (2001): «En busca del tiempo perdido: la conquista del mercado exterior y el desarrollo de la industria del calzado en España en la segunda mitad del siglo XX». Revista de Historia Industrial 19-20, pp. 39-77.

Moel, E. (2002): «The American Productivity Gospel in Norway: A Matter of Politics», en D. Barjot (ed.), Catching Up with America. Poductivity Missions and the Diffusion of American Economic and Technological Influence After the Second World War. Paris: Presse de l'Université de Paris-Sorbonne, pp. 99-112.

NAdAL, J. (1994): «La transición del zapato manual al zapato mecánico en España», en J. Nadal y J. Catalan (eds), La cara oculta de la industrialización española. La modernización de los sectores no líderes (siglos XIX y XX). Madrid: Alianza Editorial, pp. 321-339.

Piel. Madrid (varios años)

Piore, M. J. y SABeL, C. F. (1990): La segunda ruptura industrial. Madrid: Alianza.

Productividad. Revista de la CNPI. Madrid (varios años).

Puig, N. (2002): «Educating Spanish Managers. The United States, Modernizing Networks, and Business Schools in Spain, 1950-1975», en R. P. Adam et al. (eds.), Inside the Business School: The Content of Management Education. Oslo: Abstrakt Press, pp. 71-102.

Revista española de las industrias de la piel. Madrid (varios años).

Revista de la piel. Madrid (varios años).

SAbel, C. F. y Zeitlyn, J. (1997): World of Possibilities. Flexibility and Mass Production in Western Industrialization. Cambridge: Cambridge University Press.

SCHRÖtER, H. G. (2002): «What Is Americanisation? Or About the Use and Abuse of the Americanisation-Concept», en D. Barjot, I. Lescent-Giles y M. De Ferrière (eds.), L'Américanisation en Europe au XXe siècle: Économie, culture, politique. Volume 1. Lille: Université Charles de Gaulle, pp. 41-57.

Scranton, P. (1998): Endless Novelty. Specialty Production and American Industrialization, 1865-1925. Princeton: Princeton University Press.

Segreto, L. (2002): «The Impact of the US Productivity Philosophy in Italy After the Second World War», en D. Barjot (ed.), Catching Up with America. Poductivity Missions and the Diffusion of American Economic and Technological Influence After the Second World War. Paris: Presse de l'Université de Paris-Sorbonne, pp. 135-146.

Szenberg, M., Lombardi, J. W. y Lee, E. Y. (1977): Welfare Effects of Trade Restrictions. A Case Study of the U.S. Footwear Industry. Nueva York: Academic Press.

Thomson, R. (1989): The Path to Mechanized Shoe Production in the United States. Chapel Hill: The University of North Carolina Press.

Tiratsoo, N. (2000): «The United States Technical Assistance Programme in Japan, 195562». Business History 42 (4), pp. 117-136. 
Tiratsoo, N. y Tomlinson (1993): Industrial Efficiency and State Intervention: Labour 193951. Londres: Routledge.

Tomlinson, J. (1990): «The Failure of the Anglo-American Council on Productivity». Business History 33 (1), pp. 82-92.

U. S. Bureau of Foreing and Domestic Commerce (1946): Boot and Shoe Industry Statistics. Washington: Department of Commerce.

U. S. Department of Commerce (1929a): Boot and Shoe Industry and Trade in Great Britain. Washington: Government Printing Office.

- (1929b): Boot and Shoe Industry and Trade in Germany. Washington: Government Printing Office.

- (1937): Leather Footwear. World Production and International Trade. Washington: Government Printing Office.

Viñas, A., Viñuela, J., Eguidazu, F., Pulgar, C. F. y Florensa, S. (1979): Política comercial exterior en España (1931-1975). Madrid: Servicio de Estudios del Banco Exterior de España.

Works Progress Administration (1939): Labor Productivity in the Boot and Shoe Industry. Philadelphia: Works Progress Administration, National Research Project in cooperation with Bureau of Labor Statistics, Department of Labor.

ZeituIN, J. (2000): «Introduction: Americanization and Its Limits: Reworking US Technology and Management in Post-War Europe and Japan», en J. Zeitlin y G. Herrigel (eds.), Americanization and Its Limits. Reworking US Technology and Management in PostWar Europe and Japan. Oxford: Oxford University Press, pp. 1-50. 